(2) Open Access Full Text Article

REVIEW

\title{
Managing an outpatient parenteral antibiotic therapy team: challenges and solutions
}

This article was published in the following Dove Press journal:

Therapeutics and Clinical Risk Management

18 June 2014

Number of times this article has been viewed

\author{
Jenana Halilovic' \\ Cinda L Christensen ${ }^{2}$ \\ Hien H Nguyen ${ }^{3}$ \\ 'University of the Pacific Thomas \\ J Long School of Pharmacy, \\ Stockton, CA, USA; ${ }^{2}$ Department of \\ Pharmaceutical Services, University \\ of California, Davis Health System, \\ Sacramento, CA, USA; ${ }^{3}$ Division \\ of Infectious Diseases, Section of \\ Hospital Medicine, University of \\ California, Davis Health System, \\ Sacramento, CA, USA
}

\begin{abstract}
Outpatient parenteral antimicrobial therapy (OPAT) programs should strive to deliver safe, cost effective, and high quality care. One of the keys to developing and sustaining a high quality OPAT program is to understand the common challenges or barriers to OPAT delivery. We review the most common challenges to starting and managing an OPAT program and give practical advice on addressing these issues.
\end{abstract}

Keywords: OPAT, quality, safety, program management

\section{Introduction}

To meet the challenges of modern health care, health systems must continue to develop programs that deliver safe, cost effective, and high quality patient care. Outpatient parenteral antimicrobial therapy (OPAT) has long been considered a model that has the potential to meet the present health care challenges. However, with every innovation comes risk that must be managed properly to mitigate the potential for patient harm. These risks have been described in detail ${ }^{1}$ and more recently there has been a movement to develop a bundle to measure the quality of OPAT delivery. ${ }^{2}$ Most OPAT guidelines review published studies and expert opinion on the delivery of OPAT without necessarily addressing some of the more practical issues around program management. ${ }^{3}$ In this paper, we review some of the most common challenges to starting and managing an OPAT program and give practical advice on addressing these common issues.

\section{The OPAT team \\ Challenge}

Who should be on the OPAT team and how does the OPAT team work together to determine that a patient is an appropriate candidate for OPAT?

\section{Solution}

The OPAT service is responsible for evaluating and selecting appropriate candidates for OPAT. Several different models of OPAT service have been reported in the literature. ${ }^{4-7}$ Good Practice Recommendations from the United Kingdom recommend that the OPAT service, at a minimum, consists of a medically qualified clinician/ infection specialist, a specialist nurse, and clinical antimicrobial pharmacist. ${ }^{8}$ The Infectious Diseases Society of America (IDSA) guidelines recommend that the OPAT health care team includes an infectious diseases (ID) physician, primary
Correspondence: Hien H Nguyen UC Davis Health System,

Patient Support Services Building Suite 500, 4I50V Street, Sacramento, CA, USA 95817

Email hien.nguyen@ucdmc.ucdavis.edu
Therapeutics and Clinical Risk Management 20I4:I0 459-465 
care or referring physicians, nurse, pharmacist, and case manager or billing staff knowledgeable about therapeutic issues and third party reimbursements. ${ }^{3}$ While each institution may have a slightly different OPAT team setup, a multidisciplinary approach with expertise and experience in antimicrobial therapy is critical to the success and safety of the service. Antimicrobial stewardship is an important component in this process as it can lead to antimicrobial recommendations that improve efficacy, safety, cost, and in certain circumstances, provide oral therapy alternatives and may even help avoid OPAT altogether. ${ }^{6}$ The most important members of the OPAT team are the patient and his caregiver because they must replace traditional health care workers and become active participants in their care.

In order to determine whether a patient is an appropriate candidate for OPAT (and be a member of the OPAT team), the OPAT service should first assess the patient to confirm that intravenous (IV) antimicrobial therapy is truly necessary with no suitable alternative oral agents. Next, the OPAT service should ensure that the patient is fully aware of the risks and benefits of OPAT, is both willing and capable (physically and mentally) of performing OPAT for the full duration of its course, is being discharged to a safe home environment with adequate support, and has no other contraindications that would preclude discharge from the hospital. Patients may not be considered candidates for OPAT if they have an unstable home environment (eg, homelessness), are IV drug users, do not have access to transportation and/or telephone, or whose needs would otherwise be better met as an inpatient or at a sub-acute care facility. Continuous communication between the OPAT service, primary care team, and the patient is critical in finding mutual agreement and developing a definitive treatment plan. ${ }^{2,3,8,9}$

Once an OPAT plan has been set in place, the patient and/or caregiver needs to be educated on self-administration of OPAT by an OPAT team member, home infusion service, or case manager/nurse knowledgeable in OPAT. In Figure 1, we review the steps that must be taken to make this assessment and the typical health care personnel that would be involved, although the specific duties may be divided up and performed by one or multiple members of the OPAT team.

\section{Creating a safe and effective treatment plan Challenge}

What are the options for parenteral antimicrobial infusion outside of the hospital?

\section{Solution}

Generally there are many different options to deliver OPAT, including skilled nursing facilities, dialysis centers, a doctor's office, and even daily visits to the emergency room. Each of these options confers different utilization of health resources, is influenced by individual patient medical conditions, and may be predicated on availability of resources or payer plan coverages. The two most common options for OPAT include an infusion center or a residential location, which will be discussed in the next section.

\section{Outpatient infusion center}

At an infusion center and settings where there is trained staff, the medications are usually administered by a nurse, so the patient need only be informed of potential adverse effects and cautions regarding a central catheter if one is in place. For select cases, the use of peripheral venous catheters can be utilized for short-term drug administration at an infusion center, thus avoiding the cost and potential complications of central catheter placement. Other aspects of treatment may be performed such as wound dressing changes and blood samples for laboratory tests. Patients are also observed each day, so adverse drug effects, catheter complications, and signs of infection resolution may be recognized more quickly. Because of this, daily treatment at a local infusion center may be considered a safer option than home OPAT for patients no longer needing inpatient care. The biggest obstacles to the use of an infusion center for antimicrobial administration are 7 days/week availability, reliable patient transportation, and limited drug options owing to the need for once daily administration (drug options are discussed below).

\section{OPAT at home}

One of the key points in choosing a treatment regimen in the home is to keep the plan as simple as possible. Regardless of how competent the patient or caregiver is while performing the administration technique during training, the lack of comprehensive education and experience increases the risk of important steps being forgotten or misapplied. Forgetting to flush between sequential drug administrations or touching sterile ports or syringe tips could lead to drug precipitation or catheter-related infections.

\section{Follow-up}

In order to ensure a smooth transition of care, a clear followup plan should be established between the OPAT team, referring physicians, and the patient at the time of discharge. This includes assigning a physician who will be responsible for 


\begin{tabular}{|c|c|c|}
\hline & Issues & OPAT team member \\
\hline & Safe/stable home environment & $\begin{array}{l}\text { Case management/ } \\
\text { social work }\end{array}$ \\
\hline \multirow{2}{*}{$\begin{array}{l}\text { OPAT patient identification } \\
\text { and selection }\end{array}$} & $\begin{array}{l}\text { No contraindications for } \\
\text { discharge }\end{array}$ & Physician team \\
\hline & $\begin{array}{l}\text { Aware of risks/benefits and } \\
\text { agreeable to follow-up plan }\end{array}$ & $\begin{array}{l}\text { Physician team and } \\
\text { ID physician }\end{array}$ \\
\hline \multirow[b]{2}{*}{$\downarrow$} & $\begin{array}{l}\text { No oral antimicrobial therapy } \\
\text { feasible }\end{array}$ & $\begin{array}{l}\text { Physician team and } \\
\text { ID physician }\end{array}$ \\
\hline & \multirow{2}{*}{$\begin{array}{l}\text { Drug-specific considerations: } \\
\text { safety profile, frequency of } \\
\text { administration, length of } \\
\text { infusion, drug interactions, } \\
\text { therapeutic drug monitoring, } \\
\text { cost }\end{array}$} & \multirow{2}{*}{$\begin{array}{l}\text { ID pharmacist or ID } \\
\text { physician }\end{array}$} \\
\hline OPAT selection & & \\
\hline \multirow[b]{2}{*}{$\downarrow$} & $\begin{array}{l}\text { Patient-specific considerations: } \\
\text { comorbidities, impaired renal } \\
\text { and/or liver function } \\
\text { necessitating dose adjustment }\end{array}$ & $\begin{array}{l}\text { ID pharmacist or ID } \\
\text { physician }\end{array}$ \\
\hline & \multirow{2}{*}{$\begin{array}{l}\text { Vascular access, sterile } \\
\text { technique, antimicrobial } \\
\text { preparation education }\end{array}$} & \multirow{2}{*}{$\begin{array}{l}\text { ID pharmacist or } \\
\text { home infusion } \\
\text { company }\end{array}$} \\
\hline \multirow{2}{*}{$\begin{array}{c}\text { Patient and/or } \\
\text { family/caregiver education }\end{array}$} & & \\
\hline & \multirow{2}{*}{$\begin{array}{l}\text { Aware of common and serious } \\
\text { vascular and drug-specific } \\
\text { complications/adverse effects }\end{array}$} & \multirow{2}{*}{ ID pharmacist } \\
\hline \multirow[b]{2}{*}{$\downarrow$} & & \\
\hline & $\begin{array}{c}\text { Clear communication between all } \\
\text { inpatient and outpatient services } \\
\text { (OPAT, inpatient primary team, } \\
\text { ID, home infusion, home health, } \\
\text { pharmacy, etc) }\end{array}$ & OPAT team \\
\hline Care transition & OPAT and laboratory studies & ID pharmacist or ID \\
\hline \multirow[b]{4}{*}{$\downarrow$} & ordered & physician \\
\hline & $\begin{array}{l}\text { Follow-up appointment with ID } \\
\text { or another physician with } \\
\text { expertise in OPAT in place }\end{array}$ & $\begin{array}{l}\text { Physician team and } \\
\text { case management }\end{array}$ \\
\hline & $\begin{array}{l}\text { Regular laboratory monitoring in } \\
\text { place }\end{array}$ & $\begin{array}{l}\text { ID pharmacist or ID } \\
\text { physician }\end{array}$ \\
\hline & $\begin{array}{l}\text { Clinical monitoring by an ID } \\
\text { physician or another physician }\end{array}$ & ID physician \\
\hline Outpatient monitoring & with expertise in OPAT & \\
\hline \multirow[b]{3}{*}{$\boldsymbol{v}$} & $\begin{array}{l}\text { Vascular care and line removal at } \\
\text { the completion of OPAT }\end{array}$ & ID physician \\
\hline & $\begin{array}{l}\text { Evaluation for IV to PO switch, if } \\
\text { indicated }\end{array}$ & ID physician \\
\hline & Compliance, patient satisfaction & OPAT team \\
\hline \multirow[t]{2}{*}{ OPAT program measures } & $\begin{array}{c}\text { OPAT-related } \\
\text { readmission/mortality rates }\end{array}$ & OPAT team \\
\hline & Program improvements & OPAT team \\
\hline
\end{tabular}

Figure I Proposed outline of outpatient parenteral antimicrobial therapy.

Abbreviations: ID, infectious diseases; IV, intravenous; OPAT, outpatient parenteral antimicrobial therapy; PO, oral administration.

OPAT management and setting up a follow-up visit in the outpatient setting. The actual frequency of patient follow-up seems to be highly variable in clinical practice. The IDSA OPAT guidelines state that most patients should be seen by a physician once to twice weekly, while the Good Practice Recommendation in the United Kingdom recommends weekly multidisciplinary OPAT rounds in addition to regular patient review. However, a 2004 survey conducted among ID consultants in the United States demonstrated that only $29 \%$ of the surveyed ID consultants thought that OPAT patients were being seen by a physician at least once weekly whereas $61 \%$ reported that patients were not seen this frequently (the remaining $9 \%$ did not know the frequency). ${ }^{10}$ At present, it seems that the specific frequency of follow-up is likely not a 
"one size fits all" number, but will need to be individualized with consideration to the OPAT model/resources, patient characteristics, severity of infection, and antimicrobial therapy. At a minimum, labs should be reviewed weekly and good, reliable lines of communication should be established between the clinician reviewing these safety labs and the pharmacy infusion services that generally help coordinate labs and medication changes. Timely access and review of these lab results are critical components of OPAT management programs as unavailability of labs is associated with poorer patient outcomes. ${ }^{11}$

\section{Challenge}

Devise a treatment regimen that is clinically sound, within the capabilities of the lay person administering the IV medications, and has low risk for complications.

\section{Solution}

When choosing a treatment plan, all of the usual factors such as drug allergies, potential drug interactions adverse effects, patient-specific comorbidities, and evidence for clinical efficacy should be incorporated into decision-making for OPAT. As will be discussed later, safety and tolerability become paramount in the home setting. Additionally, once or twice daily dosing and single agent therapy has also become a high priority to ensure simplicity and compliance (Table 1). A costly antimicrobial that is given once daily and has excellent tolerability may be preferred over an inexpensive alternative, if use of the costly agent results in fewer missed doses or emergency department visits for complications. ${ }^{12}$

Table I Length of intravenous (IV) infusion for antibacterials that are frequently used in outpatient parenteral antimicrobial therapy $^{\mathrm{a}}$

\begin{tabular}{lll}
\hline $\begin{array}{l}\text { IV push or } \\
\text { infusion }\end{array}$ & ${\text { IV } \text { infusion }^{\mathbf{b}}}$ & Continuous infusion \\
\hline Aztreonam & Ampicillin \pm sulbactam & Aztreonam \\
Cefazolin & Doripenem & Cefazolin \\
Cefepime & Ertapenem & Cefepime \\
Ceftazidime & Gentamicin & Ceftazidime \\
Ceftriaxone & Imipenem & Nafcillin \\
Daptomycin & Meropenem & Penicillin \\
Flucloxacillin & Teicoplanin & Piperacillin \pm tazobactam \\
Teicoplanin & Ticarcillin \pm clavulanate & \\
& Tigecycline & \\
& Tobramycin & \\
& Vancomycin & \\
\hline
\end{tabular}

Notes: ${ }^{2}$ Stability of individual agents may vary depending on temperature and device used for administration; 니 infusions are typically administered over 30 to 90 minutes. The specific infusion time recommendations vary between specific drugs; 'continuous infusions are usually administered over 24 hours.
Knowledge of possible IV administration methods suitable for the home setting is useful in determining the best regimen for a given patient. The available options include IV slow push over 2-3 minutes, IV infusion over 30-60 minutes, or longer and continuous IV infusion. The IV push method does not require any mechanical or electronic infusion rate control device or pump and thus is generally a quick and simple technique for those antimicrobials that are safe to administer this way (Table 1). However, for some infections, rapid infusion may not provide the desired blood concentration profiles compared to prolonged infusion times. ${ }^{13}$

Intermittent and continuous infusion techniques may incorporate various mechanical or electronic rate control devices to ensure relatively accurate delivery of medication over time. Electronic syringe pumps, in-line flow regulators, and elastomeric pumps are used to infuse medication over a limited period of time. For continuous infusions, elastomeric pumps and small electronic programmable pumps with attaching IV solution cassettes are frequently used to allow for easier ambulation. The latter do not require pole mounting and can be tucked into a large pocket or backpack. ${ }^{14}$

Utilizing alternative administration techniques may simplify a clinically preferred but otherwise challenging home regimen. For example, an anti-staphylococcal penicillin may be utilized for a methicillin-susceptible Staphylococcus aureus infection if converted from infusions every 4 or 6 hours to a continuous infusion with an ambulatory pump. However, some patients who want to resume some normal activities while receiving IV therapy may not want to be attached to a pump 24 hours a day. A clinically acceptable alternative agent that can be given by IV push no more than 3 times per day may be a reasonable alternative. Including the patient and caregivers in this decision-making process will promote acceptance and compliance.

A combination of oral and IV antibiotics should be considered if this will limit the number of infusions per day. A combination of oral fluoroquinolone and a once or twice daily IV glycopeptide or daptomycin might be a simpler regimen for a mixed methicillin-resistant $S$. aureus and Gram-negative bacilli infection than a two-IV drug, multiple infusion regimen. If a clinically preferred, narrow spectrum agent cannot be selected for a given patient, then a broader spectrum option may need to be considered. However, choosing a less effective or unsubstantiated regimen for the given infection should be avoided. To lower the risk of drug-induced toxicity, the involvement of a clinical pharmacist in the OPAT planning process can ensure that the antimicrobial dosage is optimized for the patient's age, 
weight, organ function, potential drug interactions, and site of infection. Assistance with drug-level interpretation and any requisite dose adjustments will help to secure a higher level of safety during therapy. ${ }^{6,14}$ Regardless, it is crucial to recognize that safe and effective outpatient IV treatment may not be possible for all patients, and OPAT may need to be reconsidered for some individuals.

\section{Challenge}

How to minimize complications and ensure safe OPAT administration?

\section{Solutions}

OPAT-related adverse events are estimated to occur in about $25 \%$ of patients and most commonly involve antibiotic reactions, hematologic or gastrointestinal adverse effects, IV access complications, or hospital readmission. ${ }^{8}$ In order to minimize OPAT-related complications, patients need regular follow-up that includes both clinical and laboratory monitoring. At a minimum, patients need to have the intravascular device reviewed and laboratory studies performed each week. More frequent laboratory testing may be required depending on the antimicrobial drug selection and patient comorbidities. In addition to clinical and laboratory monitoring, it is important to recognize patient groups that are at particularly high risk for adverse events and/or hospital readmission. A recent study developed a prediction model for 30-day hospital readmission and identified age, aminoglycoside use, resistant organisms, and number of prior hospital discharges without IV antibiotics in the past 12 months as risk factors. ${ }^{15}$ Risk factors for readmission or adverse events identified by other studies include cardiac failure, renal failure, teicoplanin therapy, female sex, and diabetes, among others. ${ }^{16,17}$

Patient and caregiver education should include thorough hands-on instruction by a qualified instructor (usually a registered nurse) on administration technique, including patient or caregiver demonstration of all steps from start to finish. Independent IV administration should not be allowed until the patient/caregiver has successfully demonstrated correct, aseptic technique, including basic trouble shooting skills in response to pump alarms, etc. Education may be required on multiple occasions, including in the home environment, until the patient/caregiver can correctly perform all procedures. Lack of proper administration technique or catheter management can lead to serious drug-related toxicities or catheter-related thrombosis or infection. The nurse instructor should communicate to the prescriber any concerns regarding lack of patient competency to safely perform OPAT procedures so that alternative plans may be developed. ${ }^{18}$

Patient and caregiver education should also include signs and symptoms of drug toxicity and catheter-related adverse events. Antibiotics considered relatively safe in a hospital or clinic setting may become less so in the home environment without daily clinical assessment of the patient and/or laboratory tests. Recognition and management of complications could be delayed in home patients, potentially increasing morbidity when adverse events occur. First doses of antibiotics should be administered in a health care setting where resuscitative equipment and personnel are available in case anaphylaxis occurs. ${ }^{8}$

An individualized monitoring plan should be developed for each OPAT patient with consideration for patient-specific potential complications. At minimum, the plan should include the frequency of nursing and physician assessments, laboratory testing, and catheter dressing changes. Additionally, the name and contact information for the primary or specialist physician responsible for the treatment course, home nursing agency, and infusion pharmacy should be noted, as well as a confirmed patient and emergency contact telephone number. The entire treatment and monitoring plan, including hospital discharge summary and type of IV access, should be made available to all health care providers participating in the care of the patient. Good communication between all care providers and the patient are essential to avoid OPAT complications. ${ }^{2}$ For programs that may manage patients with multiple providers and home infusion companies, a weekly huddle to discuss each patient's status, safety labs, and course of therapy may help identify issues before they may cause patient harm. Some programs have developed huddles involving external home infusion entities to ensure reliable communications.

Both the IDSA and the BSAC/BIA have provided guidance on laboratory monitoring, but more robust clinical or laboratory monitoring will be warranted for some patients. At minimum, weekly blood chemistries and complete blood count should be obtained. Liver function tests and therapeutic drug monitoring will be indicated for some antibiotic regimens. ${ }^{3,8}$ Serial C-reactive protein or erythrocyte sedimentation rate assays may be desired to confirm resolving infection. Factors that might lead to more frequent lab monitoring include patient age, comorbidities, specific treatment or infection-related risks, and proximity to health care facilities. For example, administration of antimicrobials with renal toxicity risk will necessitate closer monitoring of renal function in the elderly, those with pre-existing renal 
insufficiency, or administration of concomitant nephrotoxins. All laboratory results and nursing assessments need to be routed to the treating physician and OPAT team members. Patients for whom lab test results were not available to the treating physician were significantly more likely to be readmitted to hospital. ${ }^{11}$

Lastly, reliable IV access for drug administration will also decrease the risk of therapeutic misadventures. During OPAT, catheter infection rates of $2.3 \%-5 \%$ per treatment course have been reported, and are lowest with use of tunneled central venous catheters. Other catheter-related complications can range up to $17 \%$, and either issue can lead to Emergency Department or hospital admission for catheter repair or replacement. ${ }^{4}$ Central venous access catheters are preferred over temporary peripheral catheters owing to their very low chance of tissue infiltration and drug extravasation. Tunneled central IV catheters and implanted ports have lower infection risk compared to peripherally inserted central catheters, but require a surgical procedure for placement by a physician.

\section{Challenge}

How to avoid delays in OPAT care?

\section{Solutions}

Having a standardized OPAT planning procedure and a method for early identification of potential patients can prevent delays in either hospital discharge or initiation of therapy in outpatients. Care "bundles" or a formalized stepwise pathway for OPAT have been proposed as a way to ensure favorable outcomes, but may also help to expedite the process. ${ }^{2}$

Early identification of inpatients with infections amenable to OPAT will allow for preliminary screening to determine if the patient is a potential candidate. Good communication lines between case management and the clinical team is critical. Patients with endocarditis or osteomyelitis usually require prolonged therapy and many will be clinically stable enough to finish therapy as an outpatient. Early review of such patients to determine suitability for OPAT will allow sufficient time to obtain patient acceptance and education, IV access, home nursing availability, and insurance authorization - especially prior to weekends and holidays when limited health care personnel may be available. Having a mechanism such as an electronic medical record report listing patient diagnosis or patients who have a peripherally inserted central catheter line ordered will help identify patients for early review.

\section{Challenge}

How to address funding issues for OPAT?

\section{Solutions}

In the US, the lack of a single payer system can lead to many financial or health insurance impediments during OPAT planning. Each aspect of care is subject to separate insurance authorization and including personnel in the OPAT planning process with knowledge and experience with this complex system can be invaluable. For a given patient, the drug may be reimbursed, but not the IV supplies. The patient's insurance plan may not pay for home nursing or follow-up clinic visits with an ID specialist. Planning for OPAT must take these issues into consideration, and make alternative arrangements such as blood draws for labs and catheter dressing changes at the primary physician clinic in lieu of a home nurse, and completing patient teaching prior to hospital discharge. Lack of ID physician follow-up will require a determination of whether the primary care physician has sufficient expertise to safely monitor the patient's treatment and address problems during therapy. This may be a reasonable approach with experienced ancillary OPAT providers and lowrisk infections or therapy.

Aside from the direct costs of OPAT, the cost of managing an OPAT program also deserves mention. For the most part, health systems may not view the management of infections as a service line requiring dedicated resources, management, or quality of care processes. However, the oversight and management of these patients requires significant time, collaboration, and planning to be effective. With the proper oversight, efficiencies can be gained and significant cost savings can be realized. ${ }^{6,19}$ As with many different quality efforts, a bundle of measures may be required of programs to ensure safety and quality for good OPAT outcomes.

\section{Conclusion}

Although OPAT has been around for many decades, the limiting pressures of health care have thrust it into the spotlight to help control the costs of care. As health systems begin to utilize OPAT more, there must be recognition that the process of determining the need, developing a plan, and executing that plan is potentially fraught with risks and complications that must be proactively managed. We have discussed these challenges and some of the ways in which we can overcome those challenges to continue to evolve the care of these patients.

\section{Disclosure}

The authors report no conflicts of interest in this work. 


\section{References}

1. Gilchrist M, Franklin BD, Patel JP. An outpatient parenteral antibiotic therapy (OPAT) map to identify risks associated with an OPAT service. J Antimicrob Chemother. 2008;62(1):177-183.

2. Muldoon EG, Snydman DR, Penland EC, Allison GM. Are we ready for an outpatient parenteral antimicrobial therapy bundle? A critical appraisal of the evidence. Clin Infect Dis. 2013;57(3):419-424.

3. Tice AD, Rehm SJ, Dalovisio JR, et al; IDSA. Practice guidelines for outpatient parenteral antimicrobial therapy. IDSA guidelines. Clin Infect Dis. 2004;38(12):1651-1672.

4. Barr DA, Semple L, Seaton RA. Outpatient parenteral antimicrobial therapy (OPAT) in a teaching hospital-based practice: a retrospective cohort study describing experience and evolution over 10 years. Int $J$ Antimicrob Agents. 2012;39(5):407-413.

5. Dryden M, Saeed K, Townsend R, et al. Antibiotic stewardship and early discharge from hospital: impact of a structured approach to antimicrobial management. J Antimicrob Chemother. 2012;67(9):2289-2296.

6. Heintz BH, Halilovic J, Christensen CL. Impact of a multidisciplinary team review of potential outpatient parenteral antimicrobial therapy prior to discharge from an academic medical center. Ann Pharmacother. 2011;45(11):1329-1337.

7. Shrestha NK, Bhaskaran A, Scalera NM, Schmitt SK, Rehm SJ, Gordon SM. Contribution of infectious disease consultation toward the care of inpatients being considered for community-based parenteral anti-infective therapy. J Hosp Med. 2012;7(5):365-369.

8. Chapman AL, Seaton RA, Cooper MA, et al; BSAC/BIA OPAT Project Good Practice Recommendations Working Group. Good practice recommendations for outpatient parenteral antimicrobial therapy (OPAT) in adults in the UK: a consensus statement. $J$ Antimicrob Chemother. 2012;67(5):1053-1062.

9. Seaton RA, Barr DA. Outpatient parenteral antibiotic therapy: principles and practice. Eur J Intern Med. 2013;24(7):617-623.

10. Chary A, Tice AD, Martinelli LP, Liedtke LA, Plantenga MS, Strausbaugh LJ; Infectious Diseases Society of America Emerging Infections Network. Experience of infectious diseases consultants with outpatient parenteral antimicrobial therapy: results of an emerging infections network survey. Clin Infect Dis. 2006;43(10):1290-1295.
11. Huck D, Ginsberg JP, Gordon SM, Nowacki AS, Rehm SJ, Shrestha NK. Association of laboratory test result availability and rehospitalizations in an outpatient parenteral antimicrobial therapy programme. $J$ Antimicrob Chemother. 2014;69(1):228-233.

12. Shrestha NK, Mason P, Gordon SM, et al. Adverse events, healthcare interventions and healthcare utilization during home infusion therapy with daptomycin and vancomycin: a propensity score-matched cohort study. J Antimicrob Chemother. 2014;69(5):1407-1415.

13. Slavik RS, Jewesson PJ. Selecting antibacterials for outpatient parenteral antimicrobial therapy: pharmacokinetic-pharmacodynamic considerations. Clin Pharmacokinet. 2003;42(9):793-817.

14. Petroff BJ, Filibeck D, Nowobilski-Vasilios A, Olsen RS, Rollins CJ, Johnson C. ASHP guidelines on home infusion pharmacy services. Am J Health Syst Pharm. 2014;71(4):325-341.

15. Allison GM, Muldoon EG, Kent DM, et al. Prediction model for 30-day hospital readmissions among patients discharged receiving outpatient parenteral antibiotic therapy. Clin Infect Dis. 2014;58(6):812-819.

16. Duncan CJ, Barr DA, Ho A, Sharp E, Semple L, Seaton RA. Risk factors for failure of outpatient parenteral antibiotic therapy (OPAT) in infective endocarditis. J Antimicrob Chemother. 2013;68(7):1650-1654.

17. Seaton RA, Sharp E, Bezlyak V, Weir CJ. Factors associated with outcome and duration of therapy in outpatient parenteral antibiotic therapy (OPAT) patients with skin and soft-tissue infections. Int $J$ Antimicrob Agents. 2011;38(3):243-248.

18. Eaves K, Thornton J, Chapman AL. Patient retention of training in self-administration of intravenous antibiotic therapy in an outpatient parenteral antibiotic therapy service. J Clin Nurs. 2014;23(9-10): 1318-1322.

19. Nguyen HH. Hospitalist to home: outpatient parenteral antimicrobial therapy at an academic center. Clin Infect Dis. 2010;51 Suppl 2: S220-S223.
Therapeutics and Clinical Risk Management

\section{Publish your work in this journal}

Therapeutics and Clinical Risk Management is an international, peerreviewed journal of clinical therapeutics and risk management, focusing on concise rapid reporting of clinical studies in all therapeutic areas, outcomes, safety, and programs for the effective, safe, and sustained use of medicines. This journal is indexed on PubMed Central, CAS,

\section{Dovepress}

EMBase, Scopus and the Elsevier Bibliographic databases. The manuscript management system is completely online and includes a very quick and fair peer-review system, which is all easy to use. Visit http://www.dovepress.com/testimonials.php to read real quotes from published authors. 